\title{
UN PLANO DE 1770 DE LA PLAZA MAYOR DE MÁLAGA
}

\section{A 1770 MAP OF THE PLAZA MAYOR OF MÁLAGA}

\author{
Rosario Camacho Martínez \\ Universidad de Málaga, España \\ rcamacho@uma.es
}

\begin{abstract}
Para celebrar las corridas de toros de 1770 se realizó un interesante plano de la plaza mayor de Málaga que es el más exacto que conocemos de este espacio en la Edad Moderna. El plano, que aporta muchos datos, se encuentra en el Archivo Histórico Nacional de Madrid, con documentación aneja, que ha sido completada con la existente en el Archivo Municipal de Málaga.

Palabras clave: Urbanismo, planimetría, plaza mayor, plazas de toros.
\end{abstract}

To celebrate bullfighting 1770 was made a interesting map of the square of Malaga that is the most accurate we know of this space in the Modern Age. The map, which provides a lot of data, is in the National Archives in Madrid, with accompanying documentation, has been completed with that in the Municipal Archives of Málaga.

Keywords: Town planning, surveying, main square, bullrings

Tras la conquista de Málaga por los Reyes Católicos, y por voluntad de los Repartidores, a partir de 1488 se empezó a utilizar como plaza un ensanche situado en el centro del casco urbano, que también los musulmanes utilizaron como tal, las Cuatro Calles ${ }^{1}$. Su configuración vino dada por la topografía ya que la torrentera que descendía de los cerros de Gibralfaro y del Calvario señaló con su curso sinuoso el trazado de lo que luego fue la Calle Real o de Granada y, al llegar a un lugar más llano con suave declive hacia el mar, se fue formando un paraje de cierta amplitud que en época musulmana fue el espacio donde se administraba justicia y se realizaban funciones de mercado ${ }^{2}$. Este ensanche, después reseñado

${ }^{1}$ BEJARANO ROBLES, Francisco: Los Repartimientos de Málaga. Málaga, 1985, vol. I, p. 87

${ }^{2}$ BEJARANO ROBLES, Francisco: Las calles de Málaga. Málaga, 1984, vol. I, p. 258. 
como calle "de la Plaza" al conectar con las calles de las Guardas, Real y Mercaderes, formó la Plaza de las Cuatro Calles, que se ampliaría paulatinamente.

Los años inmediatos a la incorporación de la ciudad a la corona de Castilla fueron de adaptación a las necesidades más perentorias, dándose un proceso de adaptación o adecuación de la ciudad islámica a las estructuras sociales y mentalidad religiosa de la nueva población repobladora. Fue efectiva la apropiación simbólica de los espacios islámicos que, si no se podían eliminar, había que exorcizarlos verificándose la cristianización de los edificios cultuales para su uso por la nueva fe, adaptando las mezquitas como iglesias, llegándose a una mixtificación en cierto modo rechazada pero mantenida hasta que pudieron realizarse fábricas con nuevas formas y estilos ${ }^{3}$. Esa política de apropiación y adecuación adoptada en los primeros momentos supuso una modificación de funciones en los edificios, pero el cambio político, religioso e ideológico determinó una nueva conceptualización de la ciudad y del espacio ciudadano y la introducción de determinadas tipologías que se insertan en la trama urbana existente, llegándose a la transformación de su estructura y de su imagen, que nos ofrecerá la de la ciudad-convento del Antiguo Régimen, en cuya configuración los fundamentos político-religiosos fueron factor decisivo ${ }^{4}$.

En los espacios públicos, dado el sistema jerarquizado que se trata de aplicar, la implantación del nuevo aparato administrativo según mecanismos concejiles castellanos y la procedencia de la nueva población, los modelos que se imponen son castellanos, pero no se puede hablar de un planeamiento urbanístico de acuerdo con criterios estético-formales del Renacimiento o el Barroco, sino de actuaciones puntuales ante necesidades coyunturales, una reordenación del tejido urbano y redefinición funcional del espacio ${ }^{5}$.

Los primeros datos de obras en la plaza se refieren a reparaciones en su alcantarillado, y ya en enero de 1491 el Comendador Haro, como procurador del Concejo, requería al Repartidor que hiciera efectivas las mercedes concedidas por los Reyes Católicos y señalara casas para Audiencia y Escribanías Públicas ${ }^{6}$. Pero era necesario ampliar el espacio del recinto placero y, como las funciones económicas se fueron desplazando paulatinamente a otras zonas de la ciudad, a partir de 1492 se derribaron tiendas y muchas casas en los lados norte y oeste ${ }^{7}$, implicando

${ }^{3}$ CAMACHO MARTÍNEZ, Rosario: "La Plaza mayor en Málaga y su provincia”, en Actas del Congreso Internacional La Plaza Eurobarroca. Salamanca, 1999,.p. 43.

${ }^{4}$ MIRÓ DOMÍNGUEZ, Aurora y RODRÍGUEZ ORTEGA, Nuria: "La ciudad desde los Reyes Católicos a Carlos III", en SAURET GUERRERO, Teresa: (Coord.): Patrimonio cultural de Málaga y su provincia. Málaga, 2000. vol. II, p. 59.

${ }^{5}$ Ibídem, p. 67.

${ }^{6}$ BEJARANO ROBLES, Francisco: Las calles..., op. cit., p. 261

${ }^{7}$ GARCIA RUIZ, Ma Victoria: Estructura urbana de Málaga y transformaciones tras su conquista. Tesis doctoral mecanografiada, Universidad de Málaga, 2008, pp. 299-302. 
el proyecto la construcción de una plaza porticada de madera que buscaba la regularización $^{8}$. Las obras se realizaron entre 1493 y 1495, observándose una voluntad de establecer unidad y calidad en cuanto al decoro urbano, haciéndose de acuerdo con un diseño establecido, porque fue preocupación de los Repartidores y del cabildo local velar por la nueva fisonomía de la ciudad pese a que esto suponía importantes dificultades económicas ${ }^{9}$. Pero los condicionantes prácticos limitaron el proceso de recomposición morfológica y fue imposible una renovación total manteniéndose muchos aspectos de la ciudad islámica. No obstante, la restauración de la monarquía, la implantación del nuevo aparato administrativo según los mecanismos concejiles castellanos, y la procedencia de la nueva población, determinarían como modelo de plaza la castellana, aunque la configuración formal se realizará de modo paulatino ${ }^{10}$.

Y en esta plaza que sería el espacio cívico y público por excelencia, ya en el s. XVI empezaron a aparecer los programas acordes con las nuevas funciones de representación. Por las leyes firmadas por los Reyes Católicos en 1500 sobre la obligación de los Concejos de disponer de casa propia adecuada ${ }^{11}$, en 1528 se acordó edificar en la plaza el Ayuntamiento, símbolo institucional de la ciudad, cuyas obras comenzaron en 1532 12 ; en 1548 se encargaba a Diego de Vergara proyecto de los soportales con arquerías sobre columnas de piedra en los cuatro lados, de los que sólo construyó dos el maestro Guillisasti, solicitándose nueva traza de los portales y Casa del Cabildo a Luis Machuca en 1554, interviniendo también los maestros cordobeses Hernán Ruiz y Morales para la realización de ésta, que demolería más tarde el Corregidor Trexo y Monroy ${ }^{13}$. En 1633 el albañil Salvador

En este trabajo se realiza una revisión modélica de la estructura y población de Málaga a través de los libros de Repartimientos de Málaga.

${ }^{8}$ RUIZ POVEDANO, José María: Poder y sociedad en Málaga, la formación de la oligarquía ciudadana a fines del s. XV. Málaga, 1989, pp. 35 y ss.

${ }^{9}$ GARCIA RUIZ, M ${ }^{\text {a }}$ Victoria: Estructura urbana..., op. cit., p. 291. RUIZ POVEDANO, José María: Poder..., op. cit. p. 328.

${ }^{10}$ MIRÓ DOMÍNGUEZ, Aurora y RODRIGUEZ ORTEGA, Nuria: "La ciudad..., op. cit., pp. 74 y ss. CAMACHO MARTÍNEZ, Rosario: "La Plaza Mayor en Málaga y...”, op. cit., pp. 45 y ss.

${ }^{11}$ GARCIA FERNÁNDEZ, José Luis e IGLESIAS ROUCO, Lena Saladina: $L a$ plaza en la ciudad y otros espacios significativos. Madrid, 1986, p. 27.

${ }^{12}$ Inicialmente para instalar el Ayuntamiento los Repartidores cedieron una madraza por detrás de la mezquita, en lo que sería la calle Postigo de los Abades y se trasladó una vez construido el edificio de la plaza (BEJARANO ROBLES, Francsico: Los Repartimientos..., op. cit., p. 87).

${ }^{13}$ PÉREZ DEL CAMPO, Lorenzo: "Versatilidad y eclecticismo. Diego de Vergara (h. 1499-1583) y la arquitectura malagueña del siglo XVI", Boletín de Arte no 7, 1986, pp. 81100. AGUILAR GARCÍA, María Dolores: Málaga (1487-1550): arquitectura y ciudad. Málaga, 1998, pp. 131-152. 
Cárdenas y el carpintero Fernando de Ortigüela debieron proyectar un nuevo edificio, más amplio, cuyas obras aún se documentan en 1653; configurada su fachada como un edificio-balcón en función de los actos y celebraciones que tenían lugar en la Plaza, dispuesta entre dos torres y con galería superior, estaba presidida por "la santa Imagen de Nuestra Señora"14. En los bajos quedaron instalados los servicios administrativos (Escribanías Públicas) y judiciales (Audiencia), que fueron de los primeros en instalarse en ese lugar.

En el lado N. se encontraba la Casa del Corregidor, con su torre, y junto a ella la Cárcel Pública edificada a partir de 1490 sobre el solar de unos antiguos baños árabes, que fue fortalecida y remozada en tiempos del Corregidor Carri1lo Manuel a finales del siglo XVII, pues más bien parecía "cárcel de aldea"15. En un ángulo asomaba la iglesia circular del colegio de los jesuitas, edificada sobre la ermita de san Sebastián, cuya bóveda recubierta de teja se contempla como hito de la plaza, y ya en el XVIII, tras la expulsión de esta orden sus propiedades fueron solicitadas por otras entidades como el Montepío de Socorro a los Cosecheros, el Consulado y más tarde la Sociedad Económica de Amigos del País y otras instituciones. En 1781 el Montepío se instaló en el edificio más próximo al Colegio, que albergaba unas escuelas de latinidad de los jesuitas extinguidas en $1768^{16}$ y que Antonio Valderrama había arreglado con balconadas en sus diferentes plantas, realizando José Martín de Aldehuela la portada de mármol, con sobrias columnas y capiteles con cestillos de frutas, y los emblemas del Montepío en el ático ${ }^{17}$.

La fachada este la ocupaba, desde 1650, el convento de las Agustinas cuya portada se ha conservado en el pasaje decimonónico que daba comunicación a las casas surgidas sobre su solar, cuando fue desamortizado y demolido. Arrimada a este lado, para no estorbar las funciones que se desarrollaban en la plaza se encontraba la fuente renacentista de Génova, de la que se tiene noticia en este espacio desde 1554, fecha en la que se le dio agua. Exquisita pieza italiana de mármol, con relieves de sirenas, medusas, delfines, ninfas, y rematada por un águila, en 1637 la amplió el escultor J. Micael y Alfaro con otro cuerpo centrado por Neptuno y escudos de España y de Málaga, que le imprimen sentido más local y

${ }^{14}$ Archivo Municipal de Málaga (A.M.M.) Actas Capitulares, vol. 163, fols. 396-399. CADIÑANOS BARDECI, Inocencio: "Fondos documentales para la historia del arte en Málaga y su provincia”, Boletín de Arte n 22, 2001, pp. 159-161.

15 AMATE DE LA BORDA, Christoval: Compendiosa noticia de lo que ha obrado en esta ciudad de Málaga el Excelentísimo Señor Don Fernando Carrillo Manuel, Marqués de Villafiel (Edición e introducción del facsímil a cargo Manuel OLMEDO CHECA). Málaga, 1988, p. 50..

${ }^{16}$ A.M.M. Actas Capitulares, vol. 162, fol. 47v. (30-1-1772)

${ }^{17}$ CAMACHO MARTÍNEZ, Rosario: José Martín de Aldehuela (1724-1802). Del ornato rococó a la arquitectura hidráulica. Málaga, 2014, p. 237. 
nacional, que $\mathrm{M}^{\mathrm{a}}$ Dolores Aguilar interpretó también como alegoría de los mitos del mar ${ }^{18}$.

En el lado sur, se levantaban las casas del Cabildo Eclesiástico, que proyectó Diego Delgado y construyó el cantero Miguel Meléndez, respondiendo al deseo del Cabildo de poseer un inmueble en la Plaza "donde se ven los regocijos", y "la pompa de tener casa para las funciones públicas", participando de la propaganda corporativa en este privilegiado escenario urbano ${ }^{19}$.

En la Plaza se celebraban Autos de Fe, ejecuciones cuando aquí estuvo instalada la picota $^{20}$, proclamaciones, procesiones y otras solemnidades, pero las más deseadas y populares eran las fiestas de toros, que también dejaban numerosos beneficios para la ciudad, si se gestionaban adecuadamente. De ahí la importancia de "armar" la plaza. Se trataba de lograr una "arquitectura añadida", un montaje provisional de madera con gradas, andamios, palenques, tablas que, regularizando el espacio urbano, permitirían acondicionarlo para que la gente presenciara estas celebraciones. Antes, los alarifes debían poner cuidado en la seguridad de los edificios cuyas fachadas configuraban la plaza, en los que se enganchaba todo este andamiaje, velando por la integridad de los espectadores, tema éste que preocupaba asimismo al Consejo de Castilla que trataba de normalizar estos aspectos así como la ejecución de las suertes del toreo, y en algunas ciudades también a ellos competía acomodar a los espectadores según su rango social y autoridad pública. Asimismo se debía controlar la adecuada visibilidad de los que contemplaban el espectáculo desde las ventanas y balcones, para no ser molestados por los que ocupaban las gradas o tablas sobrepuestas, que habían pagado menos. Porque a los propietarios les estaba prohibido arrendar los balcones, ventanas o torres, que quedaban en propiedad del cabildo municipal, regulándose estrictamente su valor, existiendo en casi todas las ciudades el "derecho de vistas" por el cual se obligaba a los propietarios y moradores de las casas a ceder al ayuntamiento las habitaciones con huecos hacia la plaza ${ }^{21}$.

${ }^{18}$ AGUILAR GARCÍA, María Dolores:" Mar y mito en la fuente de Génova. Málaga”, Actas del I Coloquio de Iconografía. Cuadernos de Arte e Iconografía. Tomo II, 3. Madrid, 1989, pp. 177-184.

${ }^{19}$ CAMACHO MARTÍNEZ, Rosario: El barroco en Málaga. Arquitectura y urbanismo. Col. Historia del Arte de Málaga, Málaga, Edit. Prensa malagueña, 2012, vol. 7, p. 25.

${ }^{20}$ La picota estuvo en la plaza hasta 1532 , y se decidió quitar de sitio tan principal porque resultaba discordante con el nuevo carácter asumido por la plaza, colocando un rollo de cantería en la ribera del mar (AGUILAR GARCÍA, María Dolores: "La plaza mayor de Málaga en el siglo XVI", Boletín de Arte n 9, 1988, p. 164 (Actas Cap. L. 8, fol. 114 y más 122, 134). MIRÓ DOMÍNGUEZ, Aurora y RODRIGUEZ ORTEGA, Nuria: "La ciudad..., op. cit., p. 77.

${ }^{21}$ BLASCO ESQUIVIAS, Beatriz: "La Plaza Mayor de Madrid y la celebración de festejos taurinos", en Actas del Congreso Internacional La Plaza Eurobarroca, op. cit., pp. 101-112. 
Para "armar la plaza" se realizó el plano conservado en el Archivo Histórico Nacional que estudiamos y que aporta interesantes datos.

Aunque no se puede hablar de antecedentes, cabe citar las imágenes o planos de la plaza con que contamos que, si descontamos los planos generales de la ciudad, son muy escasas. El topógrafo flamenco Antón van den Wyngaerde visitó Málaga en 1564, en el recorrido de un amplio viaje realizado por encargo de Felipe II que responde no sólo al interés real por la geografía científica sino que pretendía una verdadera reorganización del territorio de la mayor parte de la Península Ibérica y de los territorios de la Corona ${ }^{22}$; nos dejó Wyngaerde, además de dos interesantes vistas panorámicas de la ciudad, (una de ellas la bella y fiel perspectiva desde el mar), algunos apuntes, entre ellos uno de Gibralfaro y otro de la plaza pública que nos muestra un edificio alto (la Casa del Corregidor), la cárcel con el escudo de los Habsburgo, al fondo el Ayuntamiento y en primer plano la fuente de Génova, que no parece estar totalmente centrada en la plaza ya que debía dejarse despejado el espacio para las diferentes funciones ${ }^{23}$ (Figura 1).

En la colección de Originales del Ayuntamiento existe un croquis de 1571, sin escala, de las calles e inmuebles que confluyen a la plaza, un testimonio gráfico en relación con una solicitud de obras, delimitando un espacio cuadrangular muy irregular en el que se rotulan los edificios, la fuente y las calles en los ángulos; esta planta de la plaza, que no es muy exacta, es la más antigua que existe en nuestro Ayuntamiento $^{24}$ (Figura 2).

Una gran exactitud se percibe en el citado plano del Archivo Histórico Nacional que es específico de la extensión de la plaza: "Plano de la Plaza Mayor de la ciudad de Málaga en que se demuestra la disposición para corridas de toros. 1773"25, aunque más bien se debe fechar en 1770 (Figura 3).

Pero dado que la fecha reseñada en el citado expediente es 1773, arrancamos de ese año en la revisión de las Actas del Cabildo Municipal, para completar los datos del Archivo Histórico Nacional. En marzo de ese año Pedro Padilla Regalado presentó un memorial ofreciendo celebrar cuatro corridas de toros para que

DÍAZ-Y RECASENS, Gonzalo: "Plazas de Toros", en AA. VV.: Plazas de Toros, volumen editado con motivo de la exposición celebrada en Sevilla en 1992, pp. 21-24.

${ }^{22}$ NIETO, Víctor, MORALES, Alfredo J. y CHECA, Fernando: Arquitectura del Renacimiento en España, 1488-1599. Madrid, 1989, p. 286

${ }^{23}$ KAGAN, R.L.: Ciudades del Siglo de Oro. Las vistas españolas de Anton van den Wyngaerde. Madrid, 1986, p. 220.

${ }^{24}$ BARRIONUEVO SERRANO, Rosario y MAIRAL JIMÉNEZ, Carmen: Mapas, planos y dibujos del Archivo Municipal de Málaga. Málaga, 2007, pp. 264-265. (El plano de 30x40 cm. Refer. A.M.M., CO 7-13, Catálogo n 110).

${ }_{25}$ Archivo Histórico Nacional (A.H.N.). Consejos leg. 39817-1 (1773) MPD 2947 "Plaza mayor de Málaga con disposición para corridas de toros". "Dibujo en tinta y sombreado amarillo y rosa. Escala sin determinar, con anotaciones explicativas y dimensiones de los espacios en varas. 375 x $535 \mathrm{~mm}$ ". 
el producto se invirtiese en la construcción de una Pescadería, con la que no contaba Málaga, o en otra obra beneficiosa para la ciudad, lo mismo que el año anterior se había invertido en el empedrado de calles, ofreciendo entregar la misma cantidad de 11.000 r., regulando las cantidades de ventas en 30 r. cada balcón y 15 r. las ventanas, según las disposiciones emanadas del Conde Aranda, y si sobrase quedaría a beneficio del suplicante. El Ayuntamiento debía aportar, como era costumbre, la tropa para los encierros que tendrían lugar por la mañana y una de sus dehesas para que los toros pastasen y estuvieran descansados, "manteniendo la debida robustez". Según su planificación la primera corrida se celebraría en septiembre por lo que solicita le faciliten la licencia lo más rápidamente posible. La Ciudad admite la propuesta pero debía conceder la licencia el Conde Aranda quien no ve suficiente la cantidad de 11.000 r. y solicita datos sobre la regulación de precios, indicando que si la utilidad no era mucha no le parecía conveniente que se permitiesen las funciones de $\operatorname{toros}^{26}$.

En su afán de estudiar a fondo este asunto el Conde de Aranda solicita se le remita un plan que comprendiese los diferentes puestos alquilabes de la plaza y sus respectivos precios. La Ciudad acordó que informasen los Diputados encargados y mandase el Síndico "que se practique el Plan"27. Parece que las cuentas de las corridas celebradas en 1770, que conservaba el tesorero, eran muy claras y como las cantidades en que se habían ajustado los puestos no habían variado desde entonces, se preparan para enviar a Aranda, acompañadas de un plano "para cuya justificación acompaño el Plan original que por casualidad se conservaba en mi poder, que uno y otro puede conducir a que esta Ilustre Ciudad practique el informe que pide el Conde Aranda" ${ }^{28}$. Éste mandó que se sacaran a pregón las corridas, subiendo algo los precios de los puestos y que se adjudicasen al mejor postor; pero con todos estos trámites la licencia se atrasa, se acerca el verano y Padilla Regalado desiste porque ya el tiempo se ha echado encima. No obstante hay otros postores, llegándose en las pujas a 12.500 r., pero no llegaron a celebrarse las corridas ${ }^{29}$.

${ }^{26}$ A.M.M. Actas Capitulares, vol. 163, fols. 163v-165, 194v., 209, 294, 295v, 374-376.

${ }^{27}$ A.M.M. Actas Capitulares, vol. 163, fols. 294 y ss. Realmente con el término Plan lo mismo puede referirse a planificación que a plano; pero hay una planificación con informe y se remiten también a un plano, todo de 1770 .

28 A.M.M. Actas Capitulares, vol. 160, fols. 222v.-224, 261v., 265. AHN Consejos leg. 39817-1 también este legajo recoge un documento del escribano del cabildo malagueño, Gregorio Martínez de Ribera, por el que la Ciudad acuerda se presente al Conde de Aranda el presupuesto de 1770, y la carta de la Ciudad poniendo "en manos de V. E. el testimonio y plan que justifica el número de varas de que se componen las varas de los diferentes puestos alquilables".

29 A.M.M. Actas Capitulares, vol. 163, fols. 377 y ss. 
El plano de la plaza mayor de Málaga es un dibujo a tinta sombreado en amarillo y rosa con anotaciones explicativas de las diferentes viviendas y calles y mide 375 x $535 \mathrm{~mm}$. No se determina la escala pero cuenta con una doble medición: la de las cuatro fachadas en general, además de las dimensiones de los diferentes espacios de cada una de ellas, dibujando en estos casos la escala gráfica en varas castellanas. Tampoco se indica la autoría, pero normalmente estos planos eran realizados por los alarifes municipales, que lo eran en ese año Juan García y Antonio de Chaes. Sin embargo el plano presenta una perfección que supera los esquemas más simples realizados por los alarifes y, dado que en otras obras colabora con ellos el arquitecto Miguel del Castillo, que fue más tarde alarife de la ciudad, no sería descartable su participación, si bien es cierto que no he encontrado ningún pago a su nombre por este trabajo ${ }^{30}$.

A través del plano tenemos constancia de la disposición trapezoidal del espacio de la plaza ( 2 varas de diferencia de las fachadas más cortas), algo que no se observaba en los planos generales de la ciudad, pero aquí la medición es muy rigurosa $^{31}$. No hay un levantamiento tan detallado de las fachadas como en el famoso plano de la plaza de San Francisco de Sevilla de $1730^{32}$, pero sí se dibujan con perspectiva caballera un tanto ingenua los hitos más representativos: la fachada de las Casas del Cabildo con la capilla del Santo Cristo en el ángulo más meridional ${ }^{33}$, la del convento de las Agustinas y la planta de la fuente, que había quedado arrimada a la fachada oriental desde el siglo XVII, el toril, además de señalar algunas casas como la del cabildo catedralicio, el marqués de Casapalma, la del conde de Aguilar, la de las Sras. Villalonas, la del librero y la Cárcel, así como las embocaduras de las cuatro calles. En el centro se dibuja una enorme argolla, que no parece corresponder a la escala del plano ${ }^{34}$.

${ }^{30}$ A.M.M. Caja 588 (leg. 112) (Cuentas del tesorero Diego de Mesa).

${ }^{31}$ Hay que reseñar que la descripción que se realiza en el informe de D. Pedro Pacheco, de 1626, se dice de ella "no es la plaza grande pero casi cuadra", aunque tampoco aquí se pretende una total precisión (Description de la Ciudad de Málaga y su playa y lo que fortificó en ella el Sr. D. Pedro Pacheco, del Consejo de Guerra de Su Majestad. Año de 1626, Introducción de MORALES FOLGUERA, José Miguel, Universidad de Málaga, 1992, p. 24).

${ }^{32}$ DÍAZ-Y RECASENS, Gonzalo: "Plazas..., op. cit., p. 25. Otras plazas que derivan hacia el trapecio son la de Zocodover en Toledo, la que Herrera proyectó para Madrid, o la de la Corredera en Córdoba (GARCIA FERNÁNDEZ, José Luis e IGLESIAS ROUCO, Lena Saladina: La plaza en la ciudad..., op. cit., p. 28).

${ }^{33}$ La capilla del Santo Cristo estaba instalada desde 1648 en el mismo edificio del Ayuntamiento; cuando éste fue demolido en el siglo XIX se trasladó a la cercana iglesia del Colegio de San Sebastián, de la Compañía de Jesús, que funcionaba como oratorio privado desde la expulsión de esta orden.

${ }^{34}$ Desconozco el porqué de esta argolla. La fuente estaba arrimada a la fachada este para despejar el espacio de la plaza para las funciones, y no podía reseñarse así, como en el 
Comparando las medidas de éste con las del presupuesto no encajan a primera vista pero es que sólo se contabiliza el espacio alquilable, teniendo que restar los privilegios que conservaban algunas casas. Y resulta importante que gracias a esta medición del espacio para armar la plaza para las corridas de toros de 1770, y su recopilación de 1773, contamos con el plano más exacto de la plaza mayor de Málaga ${ }^{35}$.

Las corridas de 1770, organizadas por Diego del Álamo, administrador de la Casa de la Matanza, fueron muy lucidas, con dos cuadrillas de banderilleros y matadores, con los varilargueros y buenos toros ${ }^{36}$. Además, aprovechando las obras para preparar las fiestas de toros se hicieron diversas mejoras en la plaza: Las casas capitulares necesitaban reparaciones reconociéndolas los alarifes para su ejecución. El diputado de obras dio orden para que se revisaran todos los balcones y sitios de la plaza para comprobar si tenían la suficiente seguridad, y la Cárcel solicitó armar su fachada para que pudieran ver los oficiales y otras personas, voleando también una ventana, lo que no se autorizó ${ }^{37}$. Algunos dueños de casas tienen que remozarlas, incluso se habla de demolerlas y volverlas a edificar por el mal estado en que se encuentran. D. Juan Lorett y Lizarraga solicitó reforzar el cuarto piso de su casa que se había hundido y quiere ampliar su balcón, así como levantar cuatro pilares y formar una torrecilla que sirviera de desahogo, licencia que le fue concedida una vez que los alarifes comprobaron que las paredes tenían el grueso suficiente para resistir. Una obra importante fue la colocación de un balcón de hierro sobre canes en el tercer piso de las casas principales del Duque de Montellano, próximas a la Cárcel, obra que informaron favorablemente, siempre que no excediera los 40 dedos de saliente y una prudencial longitud, los arquitectos Fray Francisco de los Santos y Antonio Ramos, maestro de la Catedral, los alarifes Juan García y Antonio de Chaes y el fontanero mayor Francisco de Rojas ${ }^{38}$.

En cuanto a los beneficios generales aportados por estas corridas de 1770, se invirtieron en el empedrado de diversas calles que estaban muy necesitadas de ello: parte de la plaza de la Merced, calles de Granada, Álamos y Carreterías y la entrada de la de Ollerías, quedando un sobrante de 8.000 reales que se uniría a los beneficios de otras corridas para la misma causa. En 1771 no se celebraron corridas de toros, pero en 1772 el mismo personaje Diego del Álamo organizó

esquema de 1571. Y en esa fecha tan avanzada del siglo XVIII no tendría sentido que aludiera a la antigua picota.

35 A.M.M. Actas Capitulares, vol. 163, fols. 295 y ss. AHN Consejos leg. 39817-1 (1773) MPD 2947

${ }^{36}$ A.H.N. Consejos, leg. 39817-1.

${ }^{37}$ A.M.M. Actas Capitulares, vol. 160, fols. 275, 281v., 276 y 278.

${ }^{38}$ A.M.M. Actas Capitulares, vol. 160, fols. 273 y ss, 282-283, 270 y v. 
otras cuatro corridas, invirtiéndose los beneficios asimismo en el empedrado de las calles ${ }^{39}$.

Por todo ello la Ciudad veía favorablemente la organización de las corridas de toros en 1773, no tanto para invertir en la construcción de la Pescadería, sino para continuar con el empedrado de calles; incluso respondiendo a una solicitud del Consejo se habían enviado las justificaciones del disfrute de los balcones por los regidores y otros títulos de la ciudad. Pero el Conde Aranda no consideró suficiente el beneficio económico que suponía para la ciudad y no autorizó las corridas, que no se celebraron ese año ${ }^{40}$. En cuanto a la Pescadería, que ya se pretendía edificar desde 1752 de acuerdo con un proyecto del arquitecto Antonio Ramos, tendría que esperar. En 1774 el producto de las corridas, que organizó el mismo Diego del Álamo, sí se aplicó a la Pescadería, pero los preparativos de las obras iban lentos, en 1777 hay nuevos intentos y estaban levantados los planos, aunque no se registran obras hasta $1779^{41}$.

Fecha de recepción: 30 de septiembre de 2014

Fecha de aceptación: 28 de noviembre de 2014

${ }^{39}$ A.M.M. Actas Capitulares, vol. 162, fols. 105-106, 125, 394.

${ }^{40}$ A.M.M. Actas Capitulares, vol. 163, fols. 394-399, 407, 429 y ss.

${ }^{41}$ MORALES FOLGUERA, José Miguel: La Málaga de los Borbones, Málaga 1987, pp. 189-190. A.H.N. Consejos, leg. 39817-1. A.M.M. Actas Capitulares, vol. 164, fols. 8384, 164, 185v., 201 y v., vol. 167, fol. 717, 722, 785v.-786, Escribanías de Cabildo, leg. 1.605, fols. 241-252. 


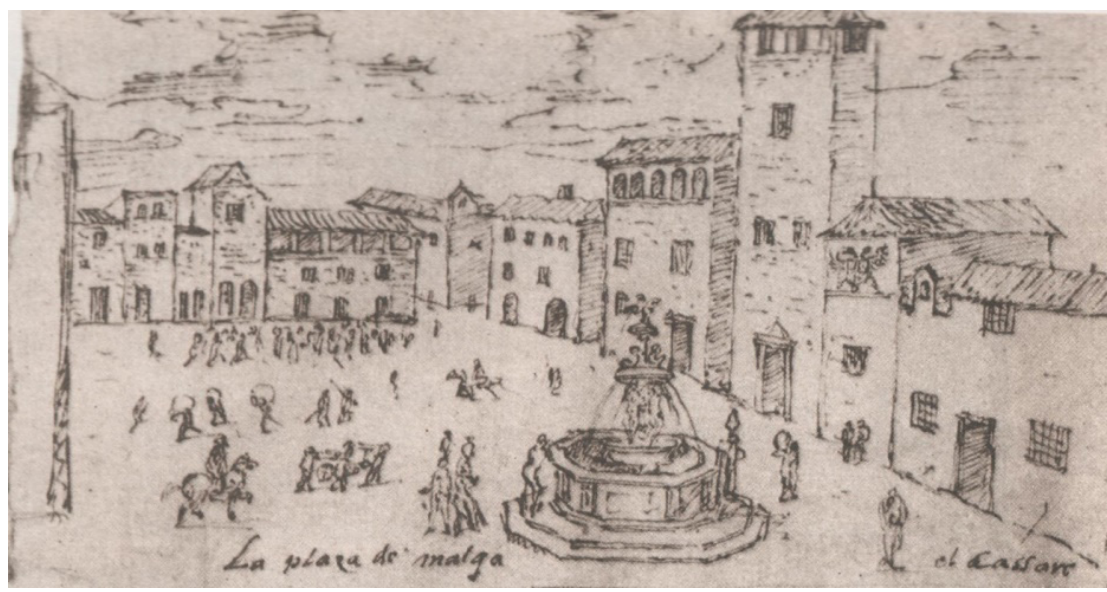

Figura 1. Plaza Mayor de Málaga. Dibujo de Anton van den Wyngaerde. (c. 1564).

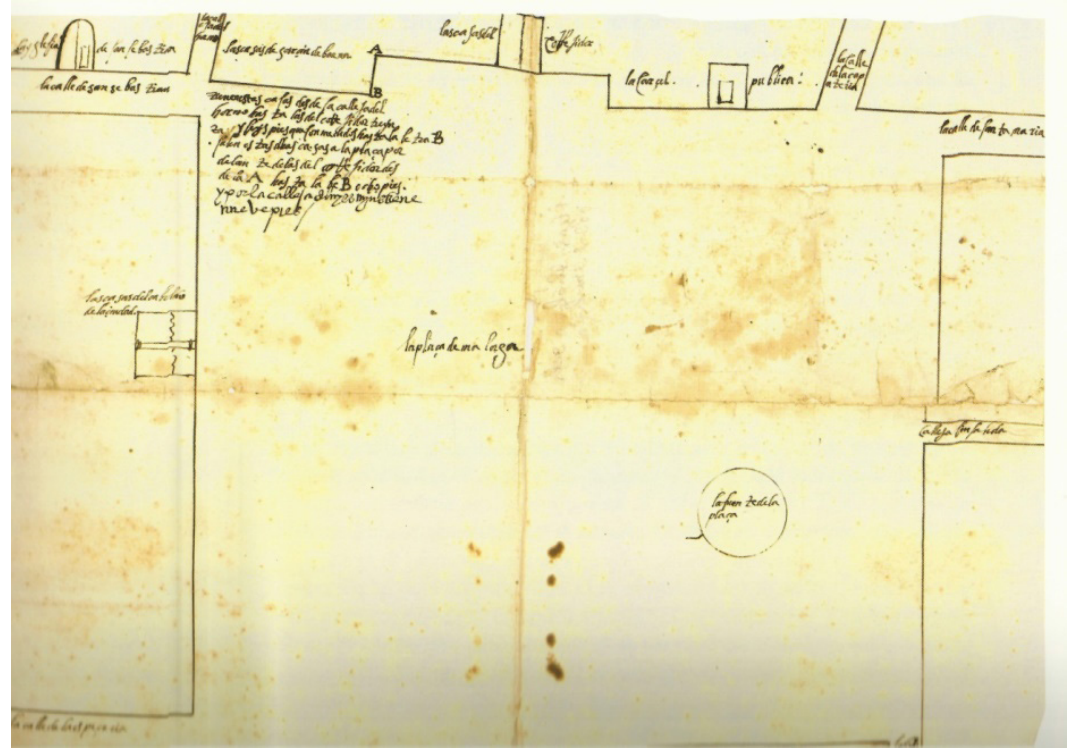

Figura 2. Plaza Mayor de Málaga. Croquis de 1571. (Archivo Municipal de Málaga). 


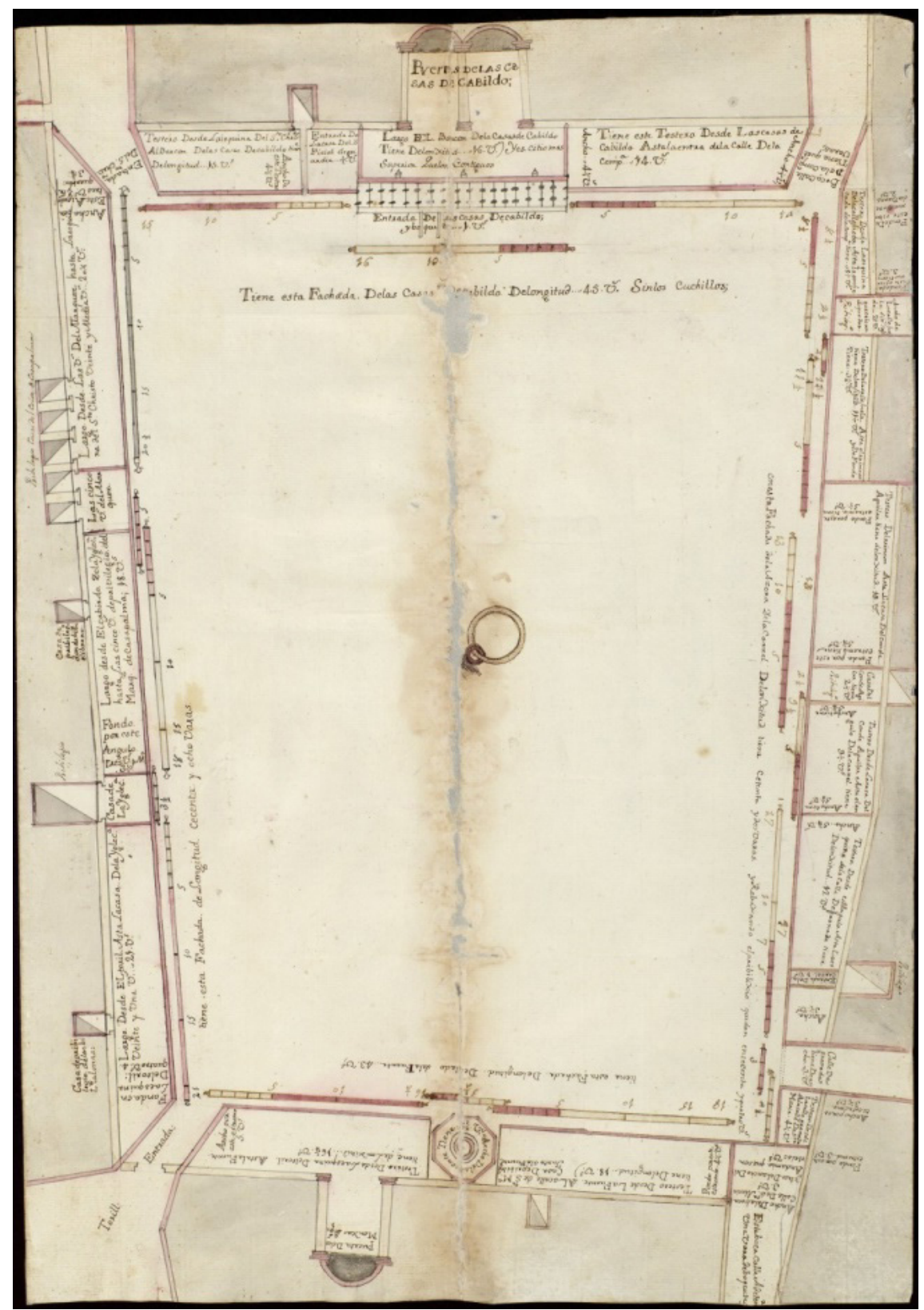

Figura 3 Plano de la Plaza Mayor de Málaga, 1770. Alarifes Municipales. (Archivo Histórico Nacional). 